\title{
La fiscalidad ambiental: auditoría a la gestión de las oficinas tributarias de los municipios de El Doncello y El Paujil en el Caquetá ${ }^{1}$
}

\author{
Ginna Tovar Cardozo ${ }^{2}$ \\ John Jairo Restrepo Lizcano ${ }^{3}$
}

Recibido: 18 de julio de 2019

Aprobado: 15 de agosto de 2019

\section{Clasificación JEL: H23}

\section{Resumen}

Los municipios tienen una gran responsabilidad frente a la gestión ambiental en virtud de su política tributaria, en especial por la administración de tributos con alguna incidencia ambiental, entre ellos los impuestos de publicidad exterior visual, sobretasa ambiental, delineación urbana, uso del espacio público y el de circulación y tránsito. Cada uno de ellos tiene una justificación en el ingreso, pero puede convertirse en una herramienta poderosa para desincentivar el consumo o corregir acciones del ciudadano, que sin pretenderlo terminan por fomentar el daño ambiental. La

1 Tovar Cardozo, G., \& Restrepo Lizcano, J. (2019). La fiscalidad ambiental: auditoría a la gestión de las oficinas tributarias de los municipios de El Doncello y El Paujil en el Caquetá. Revista Activos, 17(1), 195-233. DOI: https://doi. org/10.15332/25005278.5400

2 Contadora pública, magíster en Educación y docente catedrática de la Universidad de la Amazonia, Colombia. Correo electrónico: g.tovar@udla.edu.co.

3 Contador público, magíster en Derecho Tributario, doctorando en $\mathrm{Hu}$ manidades, Humanismo y Persona, y docente ocasional T. C. en la Universidad de la Amazonia, Colombia. Correo electrónico: jjairorestrepo@uniamazonia.edu.co 
investigación realizada se centró en evaluar, en primer lugar, la estructura organizacional de las oficinas tributarias de los municipios de El Paujil y El Doncello, del departamento del Caquetá (Colombia) y, en segundo lugar, la legalidad y conveniencia de aplicar o crear impuestos relacionados con el derecho que tienen los ciudadanos a un ambiente sano. Se realizó una investigación mixta a través de técnicas cualitativas y cuantitativas, utilizando como instrumentos la aplicación de listas de chequeo y encuestas a funcionarios, así como revisión de fuentes normativas reguladoras de los tributos en cada municipio. Los resultados dan cuenta de la existencia de falencias relacionadas con los procesos de determinación, fiscalización, liquidación y cobro coactivo de los tributos municipales, a partir de su estructura organizacional.

Palabras clave: tributos, gestión ambiental, principio de legalidad, administración tributaria.

\title{
Environmental taxation: audit of the management of the tax offices of the municipalities of El Doncello and El Paujil in Caquetá
}

\begin{abstract}
Municipalities have a great responsibility towards environmental management by virtue of their tax policy, especially for the administration of taxes with some environmental impact, including taxes on Visual Outdoor Advertising, Environmental Surcharge, Urban Delineation, Use of Public Space and of Circulation and Transit. Each of them has a justification in income, but it can become a powerful tool to discourage consumption or correct citizen actions, which without pretending to end up promoting environmental damage. The research carried out focused on assessing, first, the organizational structure of the tax offices of the municipalities of El Paujil and El Doncello of the department of Caquetá (Colombia) and,
\end{abstract}


secondly, the legality and convenience of applying or creating related taxes with the right that citizens have to a healthy environment. A mixed investigation was carried out through qualitative and quantitative techniques, using as instruments the application of checklists and surveys to officials, as well as review of regulatory sources of taxes in each municipality. The results show the existence of flaws related to the processes of determination, control, liquidation and coercive collection of municipal taxes, based on their organizational structure.

Keyword: Taxes, Environmental management, Legality principle, Tax administration.

\section{Introducción}

El Estado crea contribuciones fiscales o parafiscales justificando los recursos suficientes, sin los cuales los gobiernos no podrían financiar los bienes públicos (Schweiger, 2015), y los servicios sociales, además de garantizar a sus ciudadanos los derechos fundamentales tales como salud, educación, saneamiento básico, vivienda y trabajo, entre otros. Una nueva justificación para implementar tributos se abre paso en los Estados modernos, se trata de una categoría de tributos con fines extrafiscales, es decir, con la capacidad de orientar el comportamiento de sus ciudadanos hacia conductas plausibles por lo general asociadas al medioambiente (Eskelinen y Laitinen, 2015). Esta tipología de tributos es conocida como: impuestos verdes, impuestos ecológicos, impuestos ambientales y, ecotasas, entre otros (Albrecht, 2006, p. 303).

A pesar de los esfuerzos realizados en Colombia a través de la expedición de un amplio marco normativo que, desde los fundamentos constitucionales, contempla el medioambiente como un derecho (Const., 1991, art. 79) y promueve la educación para la protección del medioambiente (art. 67), fiscalmente se han creado una serie de mecanismos para su protección y conservación los cuales están primordialmente regulados por la Ley 99 de 
1993 como tasas retributivas y tasas compensatorias particularmente en la utilización de aguas, para riegos, vertimientos, contaminación del aire, así como la sobretasa a los peajes, impuesto al carbono y el impuesto a las bolsas plásticas, los dos últimos incorporados en la reforma tributaria de 2016.

Impuestos como el de publicidad exterior visual, sobretasa ambiental, delineación urbana, uso del espacio público, peaje turístico y el de circulación y tránsito pueden ser adoptados en los respectivos acuerdos municipales, y es función de los concejos municipales "votar los tributos y gastos legales de conformidad con la Constitución y la ley" (Const., 1991, art. 313, numeral 3). En este sentido, se plantea una reflexión a partir de los resultados de la investigación desarrollada a las oficinas administradoras de tributos en los municipios de El Paujil y El Doncello, del departamento del Caquetá, para identificar la capacidad que tienen estos entes territoriales desde su estructura organizacional, legal y tributaria, en la protección de la naturaleza, especialmente en la identificación de aquellos tributos con alguna incidencia ambiental.

En la primera parte, se distinguen las herramientas que tienen los entes territoriales para crear, administrar y cobrar tributos que gocen de reserva de ley, es decir, que tengan fuente legal en una ley expedida por el Congreso de la República, y el principio de autonomía en la ejecución de los recursos para su fin estatal. En segundo lugar, se describe la evolución que ha tenido Colombia frente a la política pública de cara a la protección de los ecosistemas, en especial su relación con las herramientas tributarias creadas por la Ley 99 de 1993. En tercer lugar, se aborda un análisis de los tributos ecológicos municipales o por lo menos aquellos diseñados para incidir en el comportamiento económico o patrón de consumo con consecuencias nocivas al medioambiente. Por último, se resaltan los principales hallazgos sobre la estructura organizacional que tienen El Doncello y El Paujil, en especial la administración de tributos que gozan de principio de legalidad. 


\section{Metodología}

La investigación realizada a las secretarías de hacienda o área responsable de la administración de los tributos en El Doncello y El Paujil es de tipo cuantitativo, y se utilizan como instrumentos para la recolección de la información objeto de análisis la encuesta personalizada y la lista de chequeo. Estos municipios pertenecen a la primera fase de la investigación, que abarca los 16 que tiene el departamento del Caquetá.

Tanto la encuesta como la lista de chequeo son herramientas propias de la investigación descriptiva. Para ello se elaboraron preguntas direccionadas en especial a los funcionarios públicos responsables de cada oficina tributaria, con facultades relacionadas en particular con los procesos de identificación, determinación, liquidación y recaudo, independientemente del tipo de contratación que presentaran, además de la verificación directa del investigador in situ.

La encuesta estaba constituida por un cuestionario de 12 preguntas, 11 cerradas y una en escala de Likert; así mismo 8 con única respuesta y 4 con múltiple respuesta. Los cuestionamientos abordados en los instrumentos estuvieron relacionados con el conocimiento de los programas y las estrategias de fiscalización aplicados por los entes territoriales, así como con la cantidad de funcionarios por cada unidad funcional en la administración de los tributos; de igual manera, se indagó sobre el nivel de educación y el perfil profesional de formación de los funcionarios, el tipo de vinculación y la antigüedad tanto en la entidad como en el cargo. También se quiso conocer sobre más recientes capacitaciones recibidas en materia tributaria y el uso de los medios tecnológicos.

Por último, la información fue tabulada en una base de datos en Excel. Se realizó un cruce de información en dos sentidos: el primero, las respuestas de la encuesta con la información aplicada a cada funcionario; y seguidamente, se confrontaron las respuestas entre los encuestados para establecer las relaciones y los aciertos entre ellos. De esta manera se establecieron las características de la estructura y funcionalidad organizacional de los entes territoriales. 


\section{La fiscalidad ambiental en los municipios de Colombia}

\subsection{Generalidades de la política pública en defensa del medioambiente}

En el informe de desarrollo humano emitido por el Programa de las Naciones Unidas para el Desarrollo (PNUD) en 1990, se trazaron objetivos para el desarrollo, y uno de ellos es crear un ambiente favorable para que la humanidad goce de una vida prolongada, saludable y creativa. La acumulación de patrimonio sumado a las ansias de poder, como lo señaló el pontífice Juan XXIII, en 1963, al predecir que la creciente carrera armamentista de algunas naciones desataría otros que quieren demostrar más poder bélico.

Valqui (2009) cree que las crisis empiezan en el siglo XXI con el capitalismo, las cuales generan desempleo, exclusión social, armamentismo, corrupción y por ende degradación ambiental. En sus palabras: "[las crisis] cuestionan y reestructuran relaciones, exacerban las violencias inherentes al capital y ponen al desnudo su naturaleza antihumana" (Valqui, 2009, p. 17). Esas crisis también fueron planteadas por la Iglesia católica cuando el papa Juan XXIII en su carta encíclica Pacem In Terris se refirió a la destrucción del medioambiente, y ocho años después el papa Pablo VI en la carta apostólica Octogesima adveniens denominó "nuevos problemas sociales" los propuestos por la economía moderna, aquellas que tienen que ver con la producción, la equidad en el comercio y en la distribución de las riquezas, al incremento del consumo y que de no resolverse pronto ponen en peligro el futuro de hombres y mujeres.

Desde hace más de 40 años en el mundo se vienen dando voces de alerta frente a la necesidad de cuidar y proteger el medioambiente, en busca de un desarrollo sostenible. En la Constitución Política del 91 se ha reconocido el derecho que tiene toda persona a gozar de un ambiente limpio, como el deber del Estado que tutele la diversidad e integridad del ambiente (Const., 1991, art. 76), ello a través del correcto manejo y aprovechamiento de los recursos naturales, que garantice el desarrollo sostenible, la conservación, 
restauración o sustitución, incluso "prevenir y controlar los factores de deterioro ambiental, imponer las sanciones legales y exigir la reparación de los daños causados" (Const., 1991, art. 80).

En concordancia con ello, se han expedido normas como la Ley 99 de 1993, con la cual se crea el Ministerio del Medio Ambiente, se ordena el sector público y se organiza el Sistema Nacional Ambiental (Sina), brindando los fundamentos de la política ambiental direccionada al sustento de procesos de desarrollo económico y social que conlleven la protección de la biodiversidad del país, lógicamente por ser patrimonio de la nación y estar relacionado con el bienestar común y la calidad de vida de los habitantes. Esta ley en su artículo 42 crea dos medidas para contrarrestar el deterioro ambiental por intervención del hombre al acudir a prácticas que atentan contra el medioambiente en la atmósfera, las fuentes hídricas y el suelo a través de basuras, aguas negras, humo, valores o cualquier sustancia nociva. La primera se denomina "tasas retributivas" y la otra "tasas compensatorias" cuya finalidad es cobrar un tributo para compensar los gastos de mantenimiento de la restauración de los recursos naturales renovables.

\subsection{Tributos ecológicos municipales}

En la actualidad no existe un impuesto para los municipios con la categoría de tributo ambiental, es decir, aquellos que se diseñan para desincentivar algún comportamiento económico, o patrones de consumo que terminan degradando el medioambiente, por ejemplo, consumir combustible fósil para la industria o los transportes, bolsas plásticas para empaques de los productos, o botellas de polipropileno con las que empacan las aguas o bebidas azucaradas. La idea es que se genere una orientación normativa para incidir en el comportamiento de las personas que termina dirigiendo colectivamente a la sociedad, en lo que Eskelinen y Laitinen (2015) denominan: "Qué tipo de conducta la comunidad política elige para alentar o desalentar entre sus miembros. Los impuestos pigovianos van proporcionando la dirección normativa en el comportamiento de los individuos" (p. 221). 
Landes (2015) en su artículo “PPor qué gravar el consumo?” estudió el trabajo de Robert Frank quien es famoso por proponer un impuesto incremental sobre el consumo. Su propuesta está motivada por el control de las externalidades posicionales, es decir, los costos que los individuos se imponen entre sí cuando consumen bienes para asegurar o adquirir un estatus social, por ejemplo, cuando se viaja en aviones a pesar del alto contenido de emisiones de efecto invernadero por la combustión del kerosene.

Los impuestos municipales están condensados en los "estatutos tributarios" aprobados mediante acuerdo municipal y estos están divididos en dos partes, a saber: la parte sustantiva que hace referencia a los tributos que pretende adoptar con descripción de todos los elementos que lo conforman; y la parte procedimental con obligaciones de los sujetos pasivos, los procesos de fiscalización, liquidación, cobro persuasivo y coactivo, discusión y devoluciones. Dicha adopción la debe hacer el respectivo municipio, siempre teniendo en cuenta que haya una ley que así lo disponga y todo porque el numeral 4 del artículo 313 y en el artículo 338 superior se dispone que el poder impositivo derivado de las entidades territoriales está condicionado a la Constitución y a la ley.

A pesar de que solo persisten unos pocos impuestos en el ámbito municipal, algunos como la sobretasa ambiental al impuesto predial, cobrado adicionalmente a los inmuebles urbanos y rurales que se encuentren en su respectiva jurisdicción, y la sobretasa ambiental para proteger los humedales y sitios Ramsar, expedidos mediante la Ley 981 de 2005, fueron creados para dotar a las corporaciones autónomas regionales (CAR) de los recursos necesarios para ser reinvertidos en la recuperación del ecosistema nativo; sin embargo, hay otro denominado peaje turístico, que se creó para dotar de recursos que permitan el ornato, el mantenimiento y la recuperación de los sitios municipales de gran valor histórico, artístico y cultural. Para Jaramillo y Villa (2003), estos "no cumplen con las características propias de los impuestos ambientales propuestos por los teóricos de la microeconomía; dentro de la hacienda pública sí opera como un impuesto" (p. 117). 
A continuación, se enuncian algunos impuestos que por sus características y su justificación se fundaron en el ingreso y no se hicieron con propósitos ambientales para proteger el ecosistema o la naturaleza, pero tienen implícito el desincentivo al consumo o a la opulencia y la riqueza.

\subsubsection{Peaje turístico}

Fuera de los creados con la Ley 99 de 1993, se aprobó para los municipios el impuesto de peaje turístico regulado por la Ley 300 de 1996, reconociendo la importancia del turismo, al considerarla una industria esencial para el desarrollo del país. La Corte Constitucional en Sentencia C-495 de 1998 lo tipifica como un ingreso no tributario creado para los municipios que necesitan proteger las construcciones y los monumentos históricos que, ubicados en las respectivas jurisdicciones municipales, hacen parte del patrimonio histórico y cultural de la nación. El artículo 72 superior ordena que estos patrimonios estén protegidos por el Estado y por esa razón se deben producir leyes que conduzcan al logro de esa finalidad.

Los elementos del peaje turístico señalan como hecho de imposición, el tránsito de vehículos por dichos territorios. El "sujeto activo" será aquel municipio con menos de cien mil habitantes y que tenga un área de gran valor histórico, artístico y cultural. El “sujeto pasivo", en quien recae el pago del tributo, es aquel viajero que con su automóvil pasa por alguno de los peajes autorizados por el Gobierno para cobrar el impuesto. La tarifa no superará un SMDLV (salario mínimo diario legal vigente) por vehículo de uso público o comercial y medio SMDLV por vehículo de uso particular. Los recaudos por este concepto "formarán parte del presupuesto de rentas y gastos del municipio y se deberán destinar exclusivamente a obras de limpieza y ornato o que conduzcan a preservar o mejorar los sitios, construcciones y monumentos históricos del municipio" (Congreso de la República de Colombia, Ley 300 de 1996, art. 25).

Si un municipio quiere que le aprueben el peaje turístico con el propósito de tener recursos para el mantenimiento del paisaje de gran valor histórico 
o de naturaleza (Aguilera, Bernal y Quintero, 2006, p. 10), será a través de los concejos municipales que elevarán una solicitud al secretario del Comité de Peajes Turísticos con el cumplimiento de los requisitos, entre ellos, tener menos de cien mil habitantes y que el área dentro del municipio tenga un atractivo turístico de gran valor histórico, artístico o cultural.

Se tienen referenciadas algunas noticias en las cuales algunos municipios como Salento (Quindío) ${ }^{4}$ y Santa Marta ${ }^{5}$ han intentado su reconocimiento, pero con resultados negativos. En solicitud enviada a inicios de 2019 al Ministerio de Comercio, Industria y Turismo, en la que se le pidió un informe o una relación de las solicitudes y los conceptos favorables expedidos a los municipios que mostraron su interés de implementar el peaje turístico desde cuando se creó la Ley 300 de 1996 (art. 25), en el que conste el nombre del municipio, el nombre del atractivo turístico de gran valor histórico, cultural o artístico, y el valor del peaje, se pudo evidenciar que este impuesto no ha sido autorizado, precisamente porque en palabras ${ }^{6} \mathrm{de}$ Juan Pablo Franky Marín, viceministro de Turismo, "desde la expedición de la ley recibimos varias solicitudes. No obstante, al solicitar el estudio de tráfico y la responsabilidad del municipio de mantener el peaje desistían de la solicitud. Es decir, a la fecha no hay conceptos al respecto".

\subsubsection{Sobretasa ambiental para proteger los humedales y sitios Ramsar}

La Ley 981 de 2005 creó una sobretasa ambiental como una forma de compensar el daño ambiental de las áreas afectadas por la construcción de

4 Sepúlveda, L. (25 de julio de 2018). Revive polémica por el cobro de 'peajes' en el Valle de Cócora. El Tiempo. Recuperado de https://www.eltiempo.com/colombia/ otras-ciudades/polemica-por-instalacion-de-peajes-en-el-valle-del-cocora-247730

5 Benjumea, P. (22 de marzo de 2017). Proponen instalar peajes turísticos en las entradas a Santa Marta. El Tiempo. Recuperado de https://www.eltiempo.com/ colombia/otras-ciudades/proponen-peajes-turisticos-en-santa-marta-70380

6 Respuesta 1-2019-002789 del 20 de febrero de 2019. Comunicación enviada por correo electrónico info@mincit.gov.co al investigador John Jairo Restrepo Lizcano. 
las vías construidas o que se llegaren a construir en los departamentos de Atlántico, Bolívar y Magdalena, en las áreas de conservación y protección municipal, sitios Ramsar o humedales de importancia internacional y reservas de biosfera y zonas de amortiguación. El pago lo hará quien transite por las vías en vehículos siempre que existan peajes o casetas recaudadoras a una tasa del $5 \%$ sobre el valor del peaje cobrado normalmente. Al igual que sucede con la tasa de peaje, este recaudo lo hace la concesionaria que administra y mantiene las vías en buen estado, y le transfiere lo correspondiente al $5 \%$ a las corporaciones autónomas regionales con influencia en el sector protegido y serán destinados para ejecutar acciones orientadas a la recuperación y conservación de dichas áreas.

En la exposición de motivos de trámite legislativo de la citada Ley 981, se evidenció la tensión que existe entre la necesidad económica de construir vías para el desarrollo del país y la de preservar los ecosistemas de la Ciénaga Grande de Santa Marta y la Ciénaga de la Virgen en Cartagena en especial porque:

La obstrucción de las bocas de oxigenación natural de las Ciénagas con ocasión de la construcción de estas obras ha provocado un gran desequilibrio en su sistema ecológico. Una situación de este tipo no puede sino perjudicar a los pobladores de la zona, cuyo sustento económico depende directamente de actividades relacionadas con este cuerpo de agua. (Congreso de la República de Colombia, Ley 981 de 2005)

En definitiva, los autores del proyecto pensaron en los costos que representa la recuperación de esos cuerpos de agua y el ecosistema que depende de él, y con el principio "quien contamina paga" o "quien destruye debe resarcir" se debe cobrar la sobretasa sobre los peajes de las vías señaladas en la Ley 981 de 2005 y en consecuencia, "no se podría fomentar la construcción de vías sobre áreas protegidas una vez sancionada, evitando con ello aumentar el daño ecológico y ampliando erróneamente el número de contribuyentes o sujetos pasivos de esta sobretasa" (Consejo de Estado, Sentencia 16527 de 2015). 
Los tributos que se enuncian a continuación, se diferencian de los dos anteriores por cuanto actualmente son cobrados en los municipios analizados en la investigación, pero tienen un componente diferenciador de otros impuestos porque el municipio estimula o desestimula comportamientos que pueden ser perjudiciales al medioambiente sano. No se habla solo de la protección de la flora y la fauna, del aire o el suelo, incluso de los cuerpos de agua, se habla específicamente del goce del espacio público, de la contaminación visual, el ruido, las vías públicas y el ornato, entre otros.

\subsubsection{Impuesto de circulación y tránsito}

El impuesto de rodamiento, también denominado circulación y tránsito, lo cobraban los municipios por cada vehículo que utilizara las vías públicas de su jurisdicción, pero es a través de la Ley 488 de 1998 que se crea el impuesto sobre vehículos automotores cuya intención del legislador fue unir tres impuestos: el de timbre nacional sobre vehículos automotores cobrado por los departamentos, el de circulación y tránsito (rodamiento) para los municipios, y el unificado de vehículos del Distrito Capital de Santa Fe de Bogotá cobrado por el Distrito para cumplir con el principio de eficiencia en el cobro de los impuestos, frente al mismo objeto de gravamen (Consejo de Estado, Sentencia 19953 de 2014).

Actualmente se cobra por la posesión de vehículos de uso particular, incluidas las motocicletas de más de 125 centímetros cúbicos, el cual es un impuesto nacional cedido a los departamentos y municipios: el primero en el $80 \%$ y el segundo en el $20 \%$ del recaudo total. Se puede caracterizar como un impuesto verde dadas las características de desincentivar el consumo de este tipo de transporte que, como sucede en Holanda, es cobrado por el peso del vehículo y no por el cilindraje, lo que redundaría en un menor consumo de combustible fósil o a base de hidrocarburos.

Este impuesto es muy importante para los municipios de Colombia porque: 1) es una forma de financiar el mantenimiento y la construcción de nuevas vías locales, 2) se garantiza la movilidad por carreteras en óptimo 
estado y señalización a los vehículos de servicio público y de servicio particular, 3) en consecuencia la ciudadanía tiene varias opciones de transporte para los que no poseen vehículos ni motocicletas, y 4) disminuye traumas y estrés a los ciudadanos por culpa de la movilidad.

Los dos municipios analizados tienen en su legislación tributaria ambos impuestos, el primero relacionado con el impuesto de circulación y tránsito, que es uno de los menos representativos porque El Paujil recaudó en 2018 el $0.4 \%$ del total de los ingresos tributarios, mientras que El Doncello no supera el $0.08 \%$ de dichos ingresos totales en el mismo año. Ahora bien, tratándose del $20 \%$ del impuesto de vehículos automotores, que deben girar los departamentos donde se encuentran matriculados los autos privados que ruedan por las calles del respectivo municipio, en el último año El Paujil logró recaudar \$17.8 millones frente a \$22 millones de El Doncello.

\subsubsection{Impuesto a la publicidad visual exterior}

Otro impuesto municipal con carácter de impuesto verde se denomina publicidad exterior visual, reglamentado a través de la Ley 140 de 1994, el cual grava el uso del espacio público para publicidad instalada a través de vallas dentro del municipio, utilizadas para divulgar o promocionar productos o mensajes por medio de dibujos, fotografías, leyendas o signos, y que sean visibles desde las vías peatonales o vehiculares. Este impuesto lo cobra el municipio a quienes anuncien cualquier mensaje por medio de una valla que supere los ocho metros cuadrados en el momento de la autorización otorgada por la oficina competente del respectivo ente territorial.

La descontaminación visual y del paisaje, al igual que la protección del espacio público son el objetivo de la Ley 140 de 1994, y a pesar de que el impuesto goza del principio de reserva de ley, y que los municipios adoptan dicho impuesto a través de los estatutos de rentas, muchas veces no saben liquidarlo, no les interesa cobrarlo, en parte por ausencia de actuación administrativa para impedir la propagación de vallas irregulares que contaminan visualmente a la ciudad. Según sentencia del 16 de agosto 
de 2011 del Consejo de Estado, el concepto del "gozo a un medioambiente sano" no alude solamente a daños contra las fuentes hídricas, aire, suelos, animales y plantas, también refiere a la contaminación auditiva y visual por ruidos, vallas, avisos y pendones colocados en la vía pública, limitando el espacio público para la libre movilización de la comunidad y desmejorando su calidad de vida.

Este impuesto trata de resolver un problema derivado de la alta contaminación visual que produce el exceso de campañas publicitarias para negocios y productos, en ocasiones por mensajes de campañas políticas y movimientos religiosos; sin embargo, hay que aclarar que este solo se cumple si la valla tiene una dimensión superior a $8 \mathrm{~m}^{2}$, lo que deja por fuera las demás dimensiones inferiores a esta y que pululan en toda la ciudad sin ningún control.

\subsubsection{Sobretasa ambiental}

La sobretasa ambiental se liquida a los propietarios de toda clase de bienes inmuebles. Como un recargo al impuesto predial unificado, tiene su origen en el artículo 317 superior en el cual la propiedad inmueble podrá ser gravada con tributos y que una parte de esos se destinarán a las encargadas del manejo y la conservación del medioambiente, entre ellas a las corporaciones autónomas regionales (CAR).

Los municipios dentro de sus estatutos de rentas podrán elegir alguna de las dos opciones que les dio la Ley 99 de 1993, a saber: i) optar por el porcentaje ambiental destinando una partida entre el 15 y el $25.9 \%$ sobre el valor calculado en el impuesto predial, o 2) calcular una sobretasa que oscila entre 1.5 y 2.5 por mil sobre la misma base que sirve para liquidar el impuesto predial. De todas formas, siempre deberá girar a la CAR regional la cuota que le corresponda según la opción aprobada por el concejo municipal.

A diferencia de reducir directamente el impacto ambiental alterando el comportamiento de los ciudadanos que pretenden acumular riqueza, Jaramillo y Villa (2003) creen que la "sobretasa ambiental utiliza un 
medio indirecto para alcanzar el mismo fin, pues (...) permite recaudar fondos por medio de una base que no está asociada directamente al daño ambiental, pero cuya destinación es exclusivamente a la recuperación del medioambiente" (p. 120).

\subsubsection{Delineación urbana}

El impuesto de delineación urbana fue creado para Bogotá mediante la Ley 97 de 1913 y posteriormente se autorizó su cobro para el resto de los municipios. Hoy la medida está vigente por medio de la Ley 14 de 1983 y el cobro se hace por la actividad de construcción, y deja al municipio la fijación de los demás elementos estructurales del impuesto en virtud del poder tributario derivado tomado de los artículos 338 y 287 superior.

La licencia de construcción es utilizada por muchos municipios como un mecanismo de control para la organización del municipio en virtud del Plan de Ordenamiento Territorial (POT). El Consejo de Estado en Sentencia 16527 de 2009 señaló que es la licencia en la cual se concreta uno de los elementos del tributo, sobre todo, si le sirve para fiscalizar el hecho imponible del impuesto de delineación urbana. Por otro lado, Restrepo (2014) definió el control urbanístico "como aquella vigilancia que ejerce el municipio para que las obras se realicen conforme a la licencia otorgada y a los Planes de Ordenamiento Territorial - POT” (p. 92).

Si bien es cierto que el impuesto se genera por la acción de construir o reparar las existentes, está claro que la licencia de construcción es el documento material con el cual se concreta la acción para ser gravada con el impuesto de delineación; sin embargo, El Paujil creó una licencia adicional denominada licencia de parcelación, contenida en el artículo 101 del estatuto tributario municipal, y que es un permiso para la creación de espacios públicos y privados, y la ejecución de obras para vías e infraestructura que garanticen la prestación de los servicios públicos domiciliarios por parte de ellas.

Otra licencia creada por el mismo municipio se denomina licencias de intervención y ocupación del espacio público, que concede una autorización 
previa para "ocupar o para intervenir bienes de uso público incluidos en el espacio público, de acuerdo con el Plan de Ordenamiento Territorial". Ambas licencias no cuentan con autorización legal para su cobro, por lo que el municipio estaría aprovechando un impuesto que carece de reserva de ley. La tarifa de este tributo ilegal es igual al $2 \%$ del valor del salario mínimo legal mensual vigente por cada metro cuadrado del área de ocupación de vías por el número de días.

\subsubsection{Rotura de vías, uso del suelo, subsuelo y escombreras}

En algunos estatutos de rentas, entre ellos los municipios de Cartagena, Popayán y Puerto Inírida, se tienen impuestos como el de uso del subsuelo en las vías públicas, que se cobra por el derecho a romper la capa asfáltica para realizar acometidas de los servicios públicos domiciliarios, o para expandir la red de alcantarillado, agua potable, energía o de telefonía fija, y redes primarias y secundarias de servicios públicos. Pasto cobra un impuesto similar, pero por utilización de escombreras cuyo hecho gravable está dado por el "descargue y disposición final de escombros, materiales, elementos, concretos y agregados sueltos, de construcción, de demolición y capa orgánica, suelo y subsuelo de excavación" (Estatuto Tributario de Pasto, art. 199).

Otro impuesto que grava la utilización del espacio público está relacionado con el impuesto de ocupación de vías y espacio público, que cobran Cartagena, Cúcuta, Mocoa, Neiva, Popayán y Tunja frente a la ocupación transitoria de las vías y los lugares públicos con andamios, materiales de construcción, casetas y lo paga el particular dueño de la obra o el servicio.

El impuesto por rotura de vías no tiene reserva de ley porque el Decreto 1333 de 1986 fue derogado expresamente por la Ley 142 de 1994. Ahora,

El tributo a la luz de las normas urbanísticas y de ordenamiento territorial tampoco tiene fundamento legal como lo expresó el Consejo de Estado en reiterada jurisprudencia, particularmente la sentencia del 18 de febrero 
de 2016, radicación 19074, MP. Jorge Octavio Ramírez. (Concepto DAF 035891 del 28 de septiembre de 2016)

Mientras El Paujil gravó dos tipos de licencias tratadas en el punto anterior y relacionadas con la construcción, El Doncello también tiene unos tributos que carecen de reserva de ley. El Acuerdo 023 del 2017, Estatuto Tributario de El Doncello, en su artículo 148 tiene los siguientes cobros: i) intervención y ocupación del espacio público con una tarifa de 2 a $6 \mathrm{SMDLV}$, ii) demarcaciones con tarifas que van desde 0.10 hasta 0.14 SMDLV, y iii) cerramientos especiales por los cuales se cobrará 0.4 SMDLV.

Relacionadas con la construcción o intervención sobre el suelo, El Doncello tiene unas multas que se activan por infracciones urbanísticas señaladas en el libro 11 del Código de Policía, que se cobra por metro cuadrado de suelo afectado o urbanizado o de intervención sobre el suelo sin los respectivos permisos. Dicha infracción puede ser de 12 a 25 SMLMV con un incremento del 25 al $100 \%$ cuando la infracción se haga en suelo de protección ambiental (Estatuto Tributario de El Doncello, art. 272). Tratándose de contaminación visual, El Doncello podrá cobrar entre 1.5 a 40 SMLMV dependiendo de la gravedad de la falta y de la cantidad de metros cuadrados utilizados en la publicidad exterior visual.

\subsection{Autonomía municipal y la estructura organizacional en Colombia}

La Constitución Política de Colombia trae consigo los primeros aspectos relacionados con la figura de la descentralización y autonomía de sus entidades territoriales. La Corte Constitucional en Sentencia C-077 de 2017, al resaltar las palabras "unitaria", "descentralizada” y "autonomía", se refiere a un nuevo modelo institucional a partir de 1991, cuando distribuye competencias entre la nación y los municipios: "Dicha distribución está enmarcada en los principios de coordinación, concurrencia y subsidiariedad (Constitución Política de Colombia, 1991, art. 288)". 
Asimismo, la Constitución define al "municipio" como la entidad fundamental de la división político-administrativa del Estado, responsable ante los habitantes de satisfacer sus necesidades básicas, garantizar servicios públicos, ejecutar obras públicas y permitir la participación ciudadana, para el desarrollo territorial y social. Estos entes deben adelantar procesos de planeación y utilizar instrumentos como los planes de desarrollo, que sirven como herramienta de planeación y control político de las acciones e inversiones que se pretendan realizar en los diferentes contextos del territorio colombiano, en virtud de la Ley 152 de 1994.

Posteriormente, ante la necesidad de brindar elementos normativos para la organización territorial, se emite la Ley 1454 de 2011, a través de la cual se regula la organización político-administrativa del territorio colombiano y se establecen los principios rectores del ordenamiento territorial, propiciando condiciones para reconocer la diversidad local, sus características y que las autoridades locales puedan determinar cuáles son sus necesidades para anticipar "las consecuencias e impactos que el ordenamiento territorial diseñado pueda tener en los habitantes de un territorio específico" (Corte Constitucional de Colombia, 2017, Sentencia C-077).

Ahora bien, a pesar de que en 1994 se crea la Ley 136, como regulación para la modernización de la organización y el funcionamiento de los municipios, posteriormente, y a partir de la Ley 1551 de 2012, se brindan los elementos para el fortalecimiento del gobierno local, se explica y desarrolla por primera vez el principio constitucional de diferencia o diversidad para la asignación de competencias, dotando de mayores herramientas a los gobiernos locales y blindando las finanzas del orden municipal; todo en busca de la configuración de un nuevo municipio, generador de dinámicas y procesos de cambio que impulsen el desarrollo local.

Esta última ley mencionada, reconoce como derecho de los municipios administrar sus recursos y adoptar los tributos, además de organizar la estructura administrativa que responda a las competencias que les son asignadas por la Constitución y la ley, entre otros. Su fuente normativa más importante la encontramos en el artículo 287 superior que les asigna 
autonomía a los entes territoriales y en consecuencia puede administrar los recursos transferidos, adoptar los tributos en virtud de su poder tributario derivado y participar de las rentas nacionales.

Sin embargo, son muchos los estudios y análisis que se han realizado a este fundamento, con el propósito de explicar si realmente los entes territoriales gozan de autonomía, entre ellos Alfonso (2015) al estudiar la descentralización y la autonomía de los municipios en Colombia, concluye que la Constitución del 91 ha generado avances en lo relacionado con la democracia y eficiencia en las regiones, pero, a pesar de ello, en materia de descentralización y autonomía territorial,

Las fuerzas políticas no permiten la trasferencia de funciones principales como la de expedir sus propias normas o destinar los recursos a arbitrio de las autoridades locales, porque se debilitaría el impulso central. Es decir, se cuenta con estado central muy fuerte. (p. 25)

De igual manera, Bechara (2015) plantea el cuestionamiento: ¿Cuál es la configuración territorial de las regiones en cuanto a su autonomía en la administración de recursos y el establecimiento de los tributos necesarios para el cumplimiento de sus funciones? En él concluye que la regionalización es propia del mismo modelo de concepción social que enmarca el Estado colombiano, ya que permite que las mismas regiones por intermedio de sus representantes puedan administrar los recursos de sus fondos y destinarlos a la recuperación económica y social de sus territorios y comunidades. Y propone la necesidad de desarrollar una ley orgánica de ordenamiento territorial.

Diferencias conceptuales entre "descentralización administrativa" y "autonomía administrativa" fueron tratadas en la Sentencia C-497A de 1994, al señalar que la autonomía se distingue de la descentralización territorial porque la primera consiste en la capacidad de gestión que tienen los municipios para planear, organizar, ejecutar y controlar sus propias actividades; la segunda se refiere a la transferencia de competencias y de recursos asignados por la Constitución y la ley. 
Dentro de la capacidad de gestión mencionada por la Corte Constitucional está implícita la estructura organizacional de los entes territoriales, es decir, que estos poseen la facultad para diseñar e implementar un sistema que defina e identifique de manera jerárquica los diferentes puestos de trabajo, así como sus funciones, las cuales deben ajustarse a las necesidades y llevar al cumplimiento del cometido estatal otorgado por la Constitución y la ley, que incluye, entre otros, la creación e implementación de los tributos y la aplicación del respectivo procedimiento para la identificación, determinación, liquidación y recaudación de estos.

La Dirección de Desarrollo Organizacional del DAFP (Departamento Administrativo de la Función Pública) analiza los resultados, efectos e impactos de la simplificación de los procesos organizacionales y la planeación institucional para el mejoramiento de los productos, bienes y servicios de las entidades públicas de los órdenes nacional y territorial. Esta entidad, mediante la Guía de rediseño para entidades del orden territorial, en su segunda versión (2018), explica las fases para diseñar o rediseñar una entidad territorial, teniendo en cuenta cuatro momentos del proceso de fortalecimiento organizacional: 1) inicio, 2) diagnóstico, 3) diseño e 4) implementación (Departamento Administrativo de la Función Pública - DAFP, p. 11).

Justamente, el problema de las entidades no se encuentra en el diseño o la arquitectura institucional requerida, si no que carecen de los instrumentos y mecanismos para proveer de manera constante recursos que garanticen su sostenibilidad. Aquí se hace inviable el proceso. Esta situación es una generalidad para los municipios que se encuentran en sexta categoría, como El Doncello y El Paujil.

En concordancia con lo expuesto, las oficinas de impuestos locales se limitan al recaudo de los tributos que de forma voluntaria pagan los contribuyentes, sin dar un valor agregado en innovación o tecnología a la gestión tributaria, con el propósito de obtener los recursos suficientes para el financiamiento del gasto público local, el cual depende representativamente de las transferencias de la nación y los recursos de crédito público (MHyCP, 2007). 
Por ello es preciso que los entes territoriales sean más eficientes en el recaudo, con la implementación de estrategias que lleven a la sostenibilidad fiscal.

\subsection{Gestión ambiental de la administración tributaria municipal}

La estructura organizacional de la Secretaría de Hacienda de El Doncello cuenta con cuatro cargos: el secretario de despacho, recaudo municipal, oficina de cobros y el ingeniero de sistemas. Sin embargo, en la práctica según los datos obtenidos al aplicar los instrumentos, son tres los cargos: secretario de despacho, cobros coactivos y fiscalización, y auxiliar de recaudo, quienes ejercen funciones directamente relacionadas con la administración de tributos.

El municipio de El Paujil no tiene una Secretaría de Hacienda. Es la Tesorería, la que coordina las actividades relacionadas con la administración de los tributos y la que tiene a cargo auxiliares administrativos. Al señalar "auxiliares administrativos" no brinda una orientación frente a las funciones que desempeñan, por ello no es posible tener evidencia de su función y su relación con los procesos de determinación, fiscalización, liquidación y cobro coactivo de los tributos en el municipio. En la práctica, la Tesorería tiene cuatro cargos: la tesorera que tiene funciones de secretaria de Hacienda, cobros coactivos y fiscalización, la auxiliar de cobro coactivo y el funcionario de recaudo.

Comparativamente, los dos municipios cuentan con un Manual de funciones y competencias laborales, que contempla la descripción de los cargos, perfiles y funciones, de acuerdo con lo plasmado en el organigrama.

En relación con los perfiles, en su mayoría los funcionarios vinculados a los cargos relacionados directamente con la administración tributaria cumplen con lo establecido en el marco normativo vigente. 
Tabla 1. Funcionarios de las oficinas de tributos de los municipios de El Doncello y El Paujil

\begin{tabular}{|c|c|c|c|c|c|}
\hline \multicolumn{4}{|c|}{ Información recolectada } & \multicolumn{2}{|c|}{ Manual de funciones } \\
\hline Municipio & Cargo & Profesión & $\begin{array}{l}\text { Antigüiedad } \\
\text { en el cargo }\end{array}$ & Perfil solicitado & Experiencia \\
\hline \multirow{4}{*}{ El Paujil } & Tesorero & $\begin{array}{l}\text { Contador } \\
\text { público }\end{array}$ & 4 años & Contador público & 1 año \\
\hline & $\begin{array}{l}\text { Apoyo cobros } \\
\text { coactivos y } \\
\text { persuasivos- } \\
\text { fiscalización }\end{array}$ & Abogada & 2 años & \multicolumn{2}{|l|}{ No existe } \\
\hline & $\begin{array}{l}\text { Cobros } \\
\text { coactivos }\end{array}$ & $\begin{array}{l}\text { Técnico } \\
\text { en auxiliar } \\
\text { contable }\end{array}$ & 6 años & $\begin{array}{l}\text { Bachiller en } \\
\text { cualquier } \\
\text { modalidad }\end{array}$ & 1 año \\
\hline & $\begin{array}{l}\text { Auxiliar de } \\
\text { recaudo }\end{array}$ & $\begin{array}{l}\text { Contador } \\
\text { público }\end{array}$ & 11 meses & $\begin{array}{l}\text { Bachiller en } \\
\text { cualquier } \\
\text { modalidad }\end{array}$ & 1 año \\
\hline \multirow[t]{3}{*}{$\begin{array}{l}\text { El } \\
\text { Doncello }\end{array}$} & Tesorero & $\begin{array}{l}\text { Contador } \\
\text { público }\end{array}$ & 1 año & $\begin{array}{l}\text { Título profesional } \\
\text { en administración } \\
\text { de empresas o } \\
\text { pública, economista, } \\
\text { contaduría pública } \\
\text { del núcleo básico en } \\
\text { conocimiento NBC } \\
\text { en: administración, } \\
\text { economía, } \\
\text { contaduría pública. }\end{array}$ & 1 año \\
\hline & $\begin{array}{l}\text { Apoyo cobros } \\
\text { coactivos y } \\
\text { persuasivos- } \\
\text { fiscalización }\end{array}$ & Abogada & 1 mes & \multicolumn{2}{|l|}{ No existe } \\
\hline & $\begin{array}{l}\text { Técnica de } \\
\text { recaudo }\end{array}$ & $\begin{array}{l}\text { Comunicación } \\
\text { social y } \\
\text { comunitaria }\end{array}$ & 5 años & Bachiller & 18 meses \\
\hline
\end{tabular}

Fuente: organigramas de ambos municipios. Elaboración propia.

$\mathrm{Al}$ confrontar los resultados obtenidos en las encuestas y listas de chequeo con lo establecido en el Manual de funciones y competencias laborales, se pudo establecer que los perfiles de los profesionales son: 
abogados, contadores, administradores de empresas y auxiliares contables; solo una funcionaria en el municipio de El Doncello que cumple la función de recaudo posee un perfil no contemplado, ya que es comunicadora social y comunitaria.

Analizadas las funciones de los cargos para las oficinas de tributos se concluye que: El Paujil cuenta con un manual que identifica claramente las funciones para los diferentes cargos relacionados con el área tributaria; a diferencia de El Doncello, en donde no se identifican las funciones para el auxiliar de recaudo y la de cobros coactivos teniendo en cuenta que estos se denominan "auxiliares administrativos" sin especificar el cargo (tabla 2), lo anterior genera confusión a la hora de establecer competencias tributarias por parte de la persona asignada. También se observa la ausencia de un cargo con función de fiscalización.

A continuación, se expone un comparativo de las funciones que debe desempeñar el responsable de la oficina administradora de tributos, sobre quien recae el proceso de planeación, coordinación y control de los procedimientos tributarios en cada uno de los municipios, poniendo énfasis en que se presentan diferencias entre los entes territoriales, frente a la denominación otorgada en su estructura organizacional y su manual de funciones.

Tabla 2. Relación de las funciones del tesorero o secretario de Hacienda

\begin{tabular}{c|c}
\hline \multicolumn{2}{c}{ Municipio } \\
\hline \multicolumn{1}{c}{ El Paujil } & \multicolumn{1}{c}{ El Doncello } \\
\hline \multicolumn{1}{c}{ Función principal } & \multicolumn{1}{c}{ Secretario de Hacienda } \\
\hline $\begin{array}{l}\text { Dirigir el área presupuestal, financiera y } \\
\text { de tesorería, formular, coordinar, contro- } \\
\text { lar e implementar el pago oportuno de las } \\
\text { obligaciones del municipio a través de la } \\
\text { adecuada gestión económica, financiera, } \\
\text { de recaudo, administración, distribu- } \\
\text { ción, ejecución y control de las rentas y } \\
\text { recursos. }\end{array}$ & $\begin{array}{l}\text { Organizar, ejecutar y evaluar las activida- } \\
\text { des de la dependencia para promover el } \\
\text { control en las operaciones financieras del } \\
\text { municipio y la presentación oportuna de } \\
\text { la información de acuerdo con las normas } \\
\text { legales vigentes. }\end{array}$ \\
\hline
\end{tabular}

Fuente: elaboración propia. 
A pesar de que solo El Doncello tiene una Secretaría de Hacienda y esta a su vez se apoya funcionalmente con una oficina de recaudo y de cobro, la alcaldía de El Paujil traslada las funciones de hacienda en el tesorero quien tiene una mayor cantidad de funciones de administración tributaria, pero ello no indica que las responsabilidades relacionadas con la liquidación, el recaudo y los procesos de cobro sean de una menor envergadura; las responsabilidades en relación con la administración de tributos es la misma, indistintamente de la denominación del cargo, pues las funciones están relacionadas de manera directa con la planeación y gestión tributaria.

Frente a las funciones ejercidas por los auxiliares administrativos que se desempeñan en las unidades de administración de los tributos, la información contemplada en los manuales de funciones se presenta en la tabla 3.

Tabla 3. Relación de las funciones de los auxiliares administrativos

\begin{tabular}{|c|c|}
\hline \multicolumn{2}{|c|}{ Municipio } \\
\hline El Paujil & El Doncello \\
\hline $\begin{array}{l}\text { Auxiliar administrativo (cobros } \\
\text { coactivos) }\end{array}$ & Auxiliar administrativo \\
\hline Función principal & Función principal \\
\hline $\begin{array}{l}\text { Realizar el cobro coactivo y la vigilancia } \\
\text { de los impuestos y obligaciones a favor } \\
\text { del municipio. }\end{array}$ & $\begin{array}{l}\text { Desarrollar los procesos, procedimientos } \\
\text { y las actividades técnicas relacionadas con } \\
\text { el recaudo de los ingresos municipales, de } \\
\text { acuerdo con la normatividad vigente. }\end{array}$ \\
\hline Auxiliar administrativo (recaudo) & Auxiliar administrativo \\
\hline Función principal & Función principal \\
\hline $\begin{array}{l}\text { Apoyar a la tesorería municipal en el } \\
\text { recaudo de los impuestos, tasas, multas y } \\
\text { contribuciones, que contribuyen al desa- } \\
\text { rrollo de los objetivos de la entidad. }\end{array}$ & $\begin{array}{l}\text { Realizar actividades de apoyo y asistencia } \\
\text { administrativa en el proceso de recaudo } \\
\text { de la Secretaría de Hacienda de acuerdo } \\
\text { con la normatividad vigente. }\end{array}$ \\
\hline
\end{tabular}




\begin{tabular}{|c|c|}
\hline Funciones esenciales & Funciones esenciales \\
\hline $\begin{array}{l}\text { Recaudar impuestos, tasas, multas, } \\
\text { derechos y contribuciones en favor del } \\
\text { municipio (predial unificado, industria y } \\
\text { comercio y complementarios, circulación } \\
\text { y tránsito, rifas y espectáculos públicos, } \\
\text { ocupación de vías, servicio de báscula, } \\
\text { sacrificio de ganado, degüello, estam- } \\
\text { pillas de prouniversidad, proancianos y } \\
\text { cultura). }\end{array}$ & $\begin{array}{l}\text { Apoyar el proceso de facturación de los } \\
\text { impuestos de industria y comercio y } \\
\text { complementarios, predial unificado, de } \\
\text { conformidad con la periodicidad y las } \\
\text { disposiciones sobre la materia. }\end{array}$ \\
\hline $\begin{array}{l}\text { Actualización de las tarjetas de kárdex } \\
\text { del pago de los impuestos de circulación } \\
\text { y tránsito de los vehículos de servicio } \\
\text { público. }\end{array}$ & $\begin{array}{l}\text { Recibir el ingreso de pagos de los ejidos } \\
\text { del municipio, degüello de ganado mayor, } \\
\text { conforme a la ley. }\end{array}$ \\
\hline $\begin{array}{l}\text { Dar buen uso y mantener actualizado } \\
\text { el programa de predial, contabilizar los } \\
\text { pagos realizados por el contribuyente } \\
\text { en el programa SIIGO, y el programa de } \\
\text { industria y comercio, para optimizar su } \\
\text { gestión de recaudo. }\end{array}$ & $\begin{array}{l}\text { Orientar al usuario en los trámites de } \\
\text { impuestos y suministrar la información } \\
\text { que le sea solicitada conforme a los proce- } \\
\text { dimientos establecidos. }\end{array}$ \\
\hline $\begin{array}{l}\text { Expedir recibos de pagos y certificaciones } \\
\text { de paz y salvo. }\end{array}$ & $\begin{array}{l}\text { Recibir y descargar los pagos del impues- } \\
\text { to predial, de industria y comercio, de } \\
\text { acuerdo con los procedimientos estableci- } \\
\text { dos por la entidad. }\end{array}$ \\
\hline $\begin{array}{l}\text { Elaborar las guías de sacrificio de ganado } \\
\text { y enviar el informe a la Gobernación los } \\
\text { cinco primeros días de cada mes. }\end{array}$ & $\begin{array}{l}\text { Sellar la boletería de las rifas municipales } \\
\text { con la periodicidad establecida. }\end{array}$ \\
\hline $\begin{array}{l}\text { Presentar a la Tesorería Municipal } \\
\text { el reporte mensual de los recaudos } \\
\text { de sobretasa ambiental con destino } \\
\text { a Corpoamazonia y de la sobretasa } \\
\text { bomberíl. }\end{array}$ & \\
\hline $\begin{array}{l}\text { Recibir el recaudo de la cuota de fomento } \\
\text { ganadero y lechero, luego se llena un for- } \\
\text { mulario de consignación de lo recaudado } \\
\text { y se presenta y paga en el banco. }\end{array}$ & \\
\hline $\begin{array}{l}\text { Generar e imprimir mensualmente las } \\
\text { facturas del impuesto de industria y } \\
\text { comercio y complementarios de avisos y } \\
\text { tableros. }\end{array}$ & \\
\hline
\end{tabular}

Fuente: Manual de funciones y competencias laborales (2016) de los municipios de El Paujil y El Doncello. 
$\mathrm{Al}$ indagar a los funcionarios frente al conocimiento del Manual de funciones y competencias laborales, específicamente sobre las funciones relacionadas con el cargo que desempeñan, en los dos municipios se obtuvo respuesta favorable. Sin embargo, un análisis profundo permite concluir que la responsabilidad de administrar tributos recae sobre una nómina que no tiene formación en asuntos fiscales.

Finalmente, en relación con los cargos y las funciones, con el propósito de conocer las competencias de cada funcionario, se indagó frente a la cantidad de los responsables por cada unidad funcional en la administración tributaria, y se encontraron los siguientes resultados:

Tabla 4. Número de funcionarios de acuerdo con las unidades funcionales en la administración tributaria

\begin{tabular}{|c|c|c|}
\hline \multirow{2}{*}{ Cuestionamiento } & \multicolumn{2}{|l|}{ Municipio } \\
\hline & El Doncello & El Paujil \\
\hline $\begin{array}{l}\text { Número de funcionarios para } \\
\text { liquidar impuesto predial. }\end{array}$ & \multirow{2}{*}{$\begin{array}{l}\text { Un funcionario. } \\
\text { Este ejerce las funciones } \\
\text { de liquidación del im- } \\
\text { puesto predial e ICA. }\end{array}$} & \multirow{2}{*}{$\begin{array}{l}\text { Un funcionario. } \\
\text { Ejerce las funciones de } \\
\text { liquidación del impuesto } \\
\text { predial e ICA. }\end{array}$} \\
\hline $\begin{array}{l}\text { Número de funcionarios para } \\
\text { liquidar el ICA. }\end{array}$ & & \\
\hline $\begin{array}{l}\text { Número de funcionarios con } \\
\text { facultades de fiscalización y } \\
\text { liquidación. }\end{array}$ & \multirow{2}{*}{$\begin{array}{l}\text { Un funcionario. } \\
\text { Quien posee las facul- } \\
\text { tades de fiscalización y } \\
\text { liquidación y cobro. }\end{array}$} & Un funcionario. \\
\hline $\begin{array}{l}\text { Número de funcionarios con } \\
\text { facultades de cobro coactivo y } \\
\text { persuasivo. }\end{array}$ & & Un funcionario. \\
\hline Jefe de Impuestos. & $\begin{array}{l}\text { Un funcionario. } \\
\text { El secretario de } \\
\text { Hacienda. }\end{array}$ & $\begin{array}{l}\text { Un funcionario. } \\
\text { El tesorero. }\end{array}$ \\
\hline
\end{tabular}

Fuente: elaboración propia.

En los dos municipios, el funcionario que tiene la responsabilidad de realizar la liquidación del impuesto predial, también la hace al ICA. En El Paujil, las facultades de fiscalización y liquidación, así como las de cobro coactivo y persuasivo, son ejercidas por dos funcionarios; es decir que estas 
se hacen de manera independiente, a diferencia de El Doncello, en donde estas dos facultades recaen sobre un mismo funcionario.

Un análisis de la información recopilada identifica que en la oficina de tributos de El Doncello se está presentando concentración de facultades en cabeza de una sola persona, toda vez que en ella recaen los procesos de fiscalización, cobro persuasivo y cobro coactivo. Aquí el funcionario es juez y parte dentro de un mismo expediente. De igual manera se constató que esta persona se encuentra vinculada mediante contratos de prestación de servicios, y según la Ley 1386 de 2010 se prohíbe que sean delegadas en particulares las funciones y facultades de administración de los tributos.

En El Paujil sucede algo similar: la persona que adelanta el proceso de fiscalización también se encuentra vinculada mediante la modalidad de contrato por prestación de servicios, pero quien realiza el cobro coactivo es una funcionaria diferente. Se identifica que no existe incompatibilidad de funciones, pero sí es necesario hacer un ajuste al cargo teniendo en cuenta la citada ley.

Frente al Plan Institucional de Capacitación - PIC, se concluyó que ningún funcionario recibió inducción frente a los procesos adelantados por las oficinas administradoras de tributos y que durante la permanencia en dichas dependencias no han recibido capacitación. Ambos municipios no cuentan con un PIC, sin embargo, de contar con él, el personal contratado mediante contratos por prestación de servicios no se beneficiaría de él, puesto que el Departamento Administrativo de la Función Pública (DAFP) ha manifestado que quienes se encuentran vinculados con esta modalidad no pueden estar incluidos dentro del proceso de capacitación (Ley 80 de 1993, y Circular Externa 100-10 de 2014 del DAFP).

También se evidenciaron situaciones riesgosas que influyen negativamente en la administración tributaria, relacionadas con los protocolos sobre el manejo del software, las bases de datos de contribuyentes y de la información relacionada con procesos adelantados. Así, ambos municipios cuentan con un programa para el registro de los contribuyentes junto con 
información de sus bases gravables. A estas bases de datos tienen acceso sin restricción la mayoría de los funcionarios que laboran en la oficina de tributos. Los resultados de la investigación revelan fallas en la seguridad de la información relacionadas con las siguientes prácticas:

- En El Paujil dos funcionarios comparten la misma clave para acceder al software de predial, con libertad para consultar y para modificar bases liquidatarias y tarifas. A pesar de que los funcionarios de El Doncello manejan diferentes claves, tienen el mismo rol en el sistema.

- El programa que liquida el impuesto predial unificado de El Paujil no realiza backup automático, y es responsabilidad de los funcionarios hacer copias de seguridad permanentemente. Este ente territorial no cuenta con un software que liquide el impuesto de industria y comercio, ya que se elabora en plantillas de Excel.

- Las copias de seguridad no se hacen correctamente, ni tienen un protocolo de seguridad definido. Se hacen semanalmente y queda en riesgo la información recogida en esos días.

- Los backup se guardan en memorias con poca capacidad de almacenamiento y no se almacenan en un servidor que garantice protección de la información. La USB es guardada en un escritorio de la oficina de recaudo.

- El municipio de El Doncello sí cuenta con un procesador que liquida ambos impuestos. Sin embargo, tiene los mismos problemas de seguridad y manejo de la información que tiene su homólogo de El Paujil.

\subsection{Impuestos ambientales en los municipios de El Doncello y El Paujil}

Los municipios gozan de poder derivado para la creación o adopción de impuestos, siempre que hayan sido creados por ley de la República (Const., 1991, arts. 150, 287, 313 y 338). A pesar de lo anterior, existen tributos que no gozan del "principio de reserva de ley", es decir, hay ausencia de una ley que lo haya creado, a pesar de que gozan de "principio de legalidad" toda vez que mientras no haya sido declarada su nulidad o suspensión en 
la jurisdicción de lo contencioso administrativo, podrán seguirse cobrando aquellos tributos.

En materia procedimental, los entes territoriales deben aplicar los procedimientos establecidos en el Estatuto Tributario para los impuestos del orden nacional de acuerdo con la Sentencia 20953 de 2017; sin embargo, estos deben constar en sus respectivos acuerdos municipales.

Al tratarse de tributos con incidencia en la gestión ambiental en los municipios de El Paujil y El Doncello, nos permite evidenciar que de los cinco tributos analizados - entre ellos, el impuesto de circulación y tránsito, el de vehículos automotores, la sobretasa ambiental, la publicidad exterior visual y el de delineación urbana-, el recaudo de todos por año alcanza a ser entre el $2 \%$ y el $4 \%$ del total de los ingresos tributarios para El Paujil en los años 2014 al 2018 (tabla 5).

De los impuestos analizados, solo el impuesto a la publicidad exterior visual no se cobra ni se presupuesta. La sobretasa ambiental se debe girar a la respectiva Corporación Autónoma Regional (Corpoamazonia), con influencia en el departamento del Caquetá y cuyos programas de conservación del medioambiente son del resorte de dicha institución. El impuesto de delineación urbana y ocupación de vías que se encuentra en el estatuto de rentas de El Paujil integra dos impuestos que son individualmente considerados: el primero - legal—, grava la ejecución de obras de construcción que se adelanten en el respectivo municipio, mientras que el segundo - no tiene fuente normativa que autorice su cobro-, grava licencias de parcelación y licencias de intervención y ocupación del espacio público.

7 Consejo de Estado. (2017). Sentencia 20953 del 6 de septiembre de 2017. Consejera Ponente: Stella Jeannette Carvajal Basto. 
224 REVISTA ACTIVoS | Ginna Tovar Cardozo, John Jairo Restrepo Lizcano

\begin{tabular}{|c|c|c|c|c|c|c|c|c|}
\hline$\stackrel{\infty}{-1}$ & 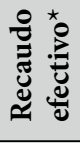 & $\begin{array}{l}8 \\
8 \\
8 \\
8 \\
1 \\
-1\end{array}$ & இి & $\begin{array}{l}\hat{\varrho} \\
\infty \\
\end{array}$ & $\begin{array}{l}\stackrel{\Xi}{\exists} \\
\widehat{\widehat{N}}\end{array}$ & 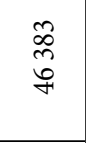 & ' & \\
\hline సี & 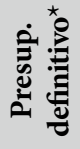 & $\begin{array}{l}8 \\
8 \\
0 \\
\infty \\
-\end{array}$ & চి & $\begin{array}{l}\stackrel{8}{8} \\
\text { ㄱ }\end{array}$ & $\begin{array}{l}8 \\
8 \\
\circ \\
\circ \\
\text { hn }\end{array}$ & $\begin{array}{l}8 \\
\text { 은 }\end{array}$ & ' & \\
\hline \multirow{2}{*}{$\stackrel{ }{\stackrel{N}{\circ}}$} & 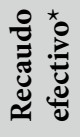 & 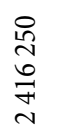 & $\begin{array}{l}\stackrel{2}{ڤ} \\
\stackrel{-}{二}\end{array}$ & $\begin{array}{l}\text { 尺 } \\
0 \\
10\end{array}$ & $\begin{array}{l}\text { Fे } \\
\text { 会 } \\
\text { ڤn }\end{array}$ & $\begin{array}{l}\text { กิ } \\
\text { nิ }\end{array}$ & ' & \\
\hline & 害泀 & 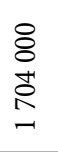 & $\begin{array}{l}\stackrel{8}{8} \\
\text { ㄱ. }\end{array}$ & $\begin{array}{l}\stackrel{8}{8} \\
\text { ㄱ }\end{array}$ & $\begin{array}{l}8 \\
8 \\
\circ \\
\text { ڤn } \\
\text { nn }\end{array}$ & $\begin{array}{l}8 \\
8 \\
8 \\
\text { 우 }\end{array}$ & ' & \\
\hline \multirow{2}{*}{ 苞 } & 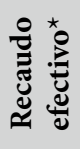 & 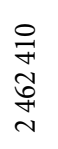 & $\underset{\infty}{\infty}$ & $\begin{array}{l}8 \\
\stackrel{8}{2} \\
2\end{array}$ & 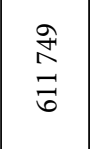 & $\begin{array}{l}\stackrel{9}{7} \\
\text { ㄱ }\end{array}$ & ' & \\
\hline & 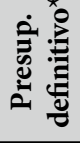 & $\begin{array}{l}\infty \\
\infty \\
心 \\
\tilde{n} \\
n\end{array}$ & $\begin{array}{l}\stackrel{8}{8} \\
\text { ㄱ. }\end{array}$ & 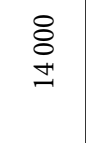 & $\begin{array}{l}8 \\
8 \\
8 \\
8\end{array}$ & \begin{tabular}{l}
$\stackrel{8}{\infty}$ \\
$+\underset{+}{+}$ \\
\multirow{+}{*}{}
\end{tabular} & ' & चु \\
\hline \multirow{2}{*}{ ᄅี } & 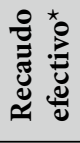 & \begin{tabular}{l}
$\stackrel{2}{N}$ \\
\multirow{2}{N}{} \\
$\sim$
\end{tabular} & $\begin{array}{l}0 \\
\infty \\
\infty \\
0 \\
0\end{array}$ & $\underset{\widetilde{F}}{\overrightarrow{7}}$ & 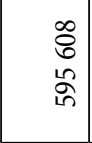 & 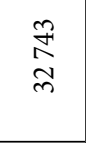 & & 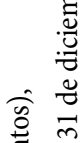 \\
\hline & 富 & $\begin{array}{l}8 \\
8 \\
\infty \\
0 \\
1 \\
-1\end{array}$ & $\begin{array}{l}8 \\
\varnothing \\
=\end{array}$ & $\begin{array}{l}\stackrel{8}{8} \\
\text { I }\end{array}$ & $\begin{array}{l}8 \\
8 \\
o \\
\text { ñ }\end{array}$ & $\begin{array}{l}8 \\
8 \\
8 \\
ㅇ ㅜ\end{array}$ & ' & 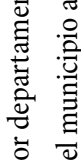 \\
\hline \multirow{2}{*}{$\underset{\nabla}{\Delta}$} & 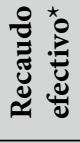 & 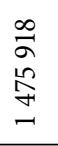 & $\begin{array}{l}\vec{i} \\
\stackrel{\sim}{n}\end{array}$ & $\underset{⿱}{\stackrel{N}{N}}$ & $\begin{array}{l}\infty \\
\infty \\
\infty \\
\infty \\
n \\
i n\end{array}$ & $\begin{array}{l}\text { L } \\
\text { \& } \\
m \\
m\end{array}$ & ' & 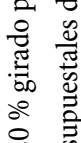 \\
\hline & 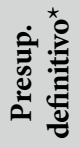 & $\begin{array}{l}8 \\
8 \\
m \\
\stackrel{+}{ \pm}\end{array}$ & $\begin{array}{l}8 \\
8 \\
\circ\end{array}$ & 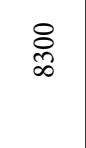 & $\begin{array}{l}8 \\
\varnothing \\
\tilde{b}\end{array}$ & $\begin{array}{l}8 \\
8 \\
\infty \\
+\infty\end{array}$ & ' & 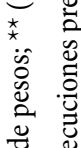 \\
\hline & 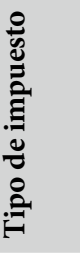 & & 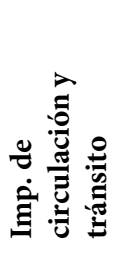 & 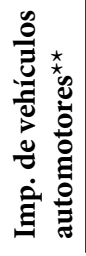 & 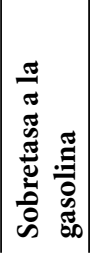 & 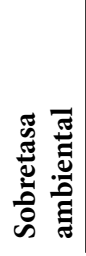 & 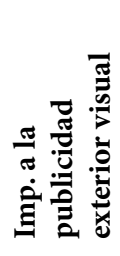 & 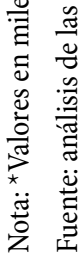 \\
\hline
\end{tabular}

Universidad Santo Tomás, Facultad de Contaduría Pública 
En el caso del recaudo en El Doncello, está un punto por encima de su vecino municipio de El Paujil, el cual es entre el 3 \% y el $5 \%$ de participación frente al recaudo total tributario para el periodo 2014-2018. Además, este municipio adoptó el impuesto a la publicidad exterior visual cuyo cobro fue inestable en los años 2014, 2016 y 2017. Asimismo, su recaudo en 2018 no alcanzó a llegar a los tres millones de pesos en todo el año (tabla 6). 
226 REVISTA ACTIVOS | Ginna Tovar Cardozo, John Jairo Restrepo Lizcano

\begin{tabular}{|c|c|c|c|c|c|c|c|c|c|}
\hline & 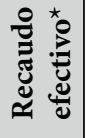 & $\begin{array}{l}\stackrel{\infty}{\infty} \\
\stackrel{0}{N} \\
\infty \\
\infty\end{array}$ & 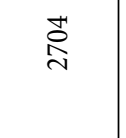 & 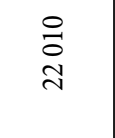 & $\begin{array}{l}\stackrel{\Xi}{二} \\
\hat{\mathrm{N}}\end{array}$ & 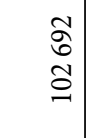 & $\begin{array}{l}\text { : } \\
\text { ¿्र }\end{array}$ & $\underset{\infty}{\stackrel{F}{W}}$ & \\
\hline ร & 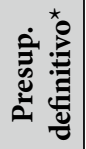 & 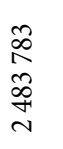 & $\frac{8}{\not}$ & 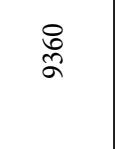 & $\begin{array}{l}8 \\
8 \\
\circ \\
\circ \\
i n n\end{array}$ & $\begin{array}{l}\stackrel{n}{\sim} \\
\stackrel{n}{n}\end{array}$ & F્ & 哭 & \\
\hline 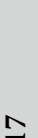 & 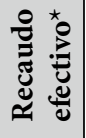 & $\begin{array}{l}\text { I } \\
\text { ळे } \\
\text { ปे }\end{array}$ & 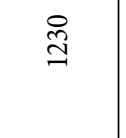 & 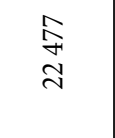 & $\begin{array}{l}\text { 今 } \\
\text { 员 } \\
\text { in }\end{array}$ & 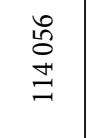 & ' & $\begin{array}{l}\Xi \\
\Xi\end{array}$ & \\
\hline ટે & 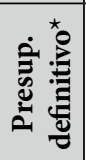 & 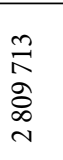 & ஓి & ஓু & $\begin{array}{l}8 \\
8 \\
\circ \\
\circ \\
\text { inn }\end{array}$ & \begin{tabular}{l}
$\stackrel{\infty}{\Xi}$ \\
in \\
\multirow{J}{*}{}
\end{tabular} & ఏ & ஓి & \\
\hline 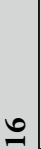 & 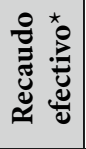 & \begin{tabular}{l} 
o \\
\&े \\
\multirow{3}{*}{} \\
v
\end{tabular} & $\stackrel{\infty}{\stackrel{\infty}{人}}$ & $\begin{array}{l}\overrightarrow{2} \\
\text { in } \\
\text { in }\end{array}$ & $\begin{array}{l}\stackrel{F}{N} \\
\vec{\sigma}\end{array}$ & $\begin{array}{l}\frac{+}{ \pm} \\
\text { ล }\end{array}$ & ' & $\begin{array}{l}\infty \\
\stackrel{\sim}{\approx} \\
\end{array}$ & 宗 \\
\hline సิ & 官泀 & $\begin{array}{l}\vec{n} \\
\hat{\alpha} \\
o \\
i n \\
\sim\end{array}$ & § & $\begin{array}{l}8 \\
\circ\end{array}$ & $\begin{array}{l}8 \\
8 \\
\text { oे }\end{array}$ & $\begin{array}{l}8 \\
8 \\
\cong \\
=\end{array}$ & 员 & $\underset{\infty}{8}$ & 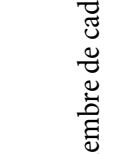 \\
\hline 12 & 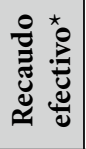 & \begin{tabular}{l}
\multirow{F}{F}{} \\
$\infty$ \\
0 \\
0 \\
$m$
\end{tabular} & 융 & $\begin{array}{l}\tilde{\sigma} \\
\text { m }\end{array}$ & 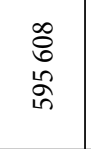 & 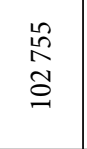 & $\underset{n}{8}$ & 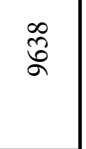 & 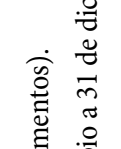 \\
\hline స & 富 & 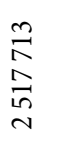 & 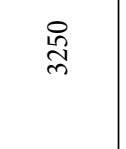 & 8 & $\begin{array}{l}8 \\
8 \\
\text { in } \\
\text { in }\end{array}$ & $\begin{array}{l}\stackrel{0}{0} \\
\stackrel{一}{=}\end{array}$ & $\stackrel{8}{\varrho}$ & ஓ̊̊ & 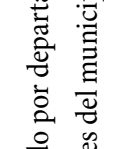 \\
\hline \pm & 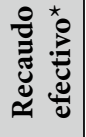 & 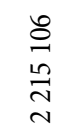 & $\begin{array}{l}\stackrel{\circ}{n} \\
\underset{n}{n}\end{array}$ & $\underset{⿱ ⺌}{\stackrel{\infty}{\leftrightarrows}}$ & $\begin{array}{l}\tilde{\infty} \\
\hat{\alpha} \\
\tilde{n} \\
\tilde{n}\end{array}$ & 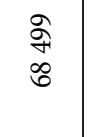 & ' & бूล & 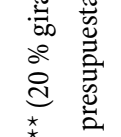 \\
\hline ก & 富: & $\begin{array}{l}\infty \\
\infty \\
+ \\
\infty \\
-1\end{array}$ & 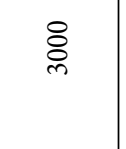 & ¿̊̊ & 은 & $\begin{array}{l}8 \\
8 \\
10 \\
\infty\end{array}$ & ষ্ণ & 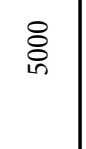 & 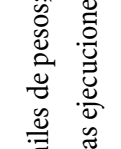 \\
\hline & 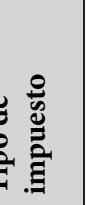 & 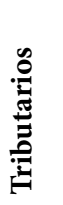 & 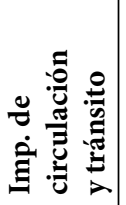 & 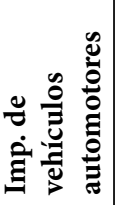 & 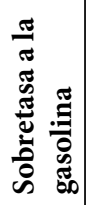 & 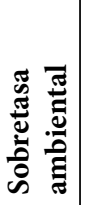 & 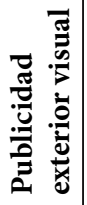 & 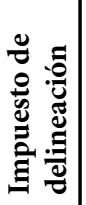 & 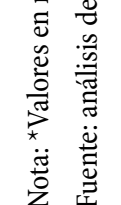 \\
\hline
\end{tabular}

Universidad Santo Tomás, Facultad de Contaduría Pública 


\section{Conclusiones}

Los municipios no cuentan con impuestos con la categoría de tributo ambiental, es decir, aquellos que se diseñan para desincentivar algún comportamiento económico, o patrones de consumo que terminan degradando el medioambiente; por eso, es importante la orientación normativa para incidir en el comportamiento de las personas que terminan dirigiendo colectivamente a la sociedad, es decir, preguntarse ¿qué tipo de conducta elige la comunidad política para alentar o desalentar a sus miembros?

La justificación para crear impuestos en el ámbito local no debe obedecer exclusivamente a una finalidad económica, sino darles prioridad a motivaciones ambientales, ya que como sucede en el impuesto de delineación, mientras más construcciones y más costosas sean, más impuesto se recaudará, lo cual provoca un reordenamiento territorial para la demanda de viviendas o construcciones urbanas. El caso también puede ilustrarse en el impuesto de circulación y tránsito, que a mayor cantidad de vehículos rodando por las calles del municipio, mayor recaudo, pero mayores daños a la infraestructura vial y a la salud humana.

Otros impuestos creados por la legislación colombiana con destino a los municipios no cumplen con su cometido ambiental, ya sea porque no los conocen o porque no les interesa, como es el caso del peaje turístico creado por la Ley 300 de 1996 para dotar de recursos necesarios en cuanto a obras de limpieza y ornato o que conduzcan a mantener el paisaje, los sitios, las construcciones y los monumentos históricos del municipio. El Doncello y El Paujil no lo cobran, lo cual es consecuente con la respuesta del viceministro de Turismo, en febrero de 2019, que desde la expedición de la ley se recibieron varias solicitudes. No obstante, al solicitar el estudio de tráfico y la responsabilidad del municipio de mantener el peaje desistían de la solicitud. Es decir, a la fecha no hay conceptos al respecto.

La suma del recaudo de los impuestos analizados (circulación y tránsito, vehículos automotores, sobretasa ambiental, publicidad exterior visual y delineación urbana) solo representa entre el $2 \%$ y el $4 \%$ del total de los 
ingresos tributarios para El Paujil entre 2014 y 2018. De los impuestos analizados, solo el impuesto a la publicidad exterior visual no se cobra ni se presupuesta. El impuesto de delineación urbana y ocupación de vías, que se encuentra en el Estatuto de Rentas de El Paujil, integra dos impuestos que al ser individualmente considerados, el primero es legal y el segundo no tiene fuente normativa que autorice su cobro. El Doncello en el recaudo alcanza a estar un punto por encima de El Paujil, que es entre el $3 \%$ y el $5 \%$ de participación frente al recaudo total tributario entre 2014 y 2018. Además, este municipio adoptó el impuesto a la publicidad exterior visual y fue inestable su cobro en 2014, 2016 y 2017, mientras que en 2018 no alcanzó a llegar a los tres millones de pesos en todo el año.

Referente a la estructura organizacional de los entes territoriales, independientemente de los diferentes marcos normativos que viabilizan la organización y reestructuración de estos, su aplicabilidad se encuentra condicionada a la disponibilidad financiera. Los municipios y más aún los de sexta categoría, no cuentan con los recursos económicos para hacer que las oficinas administradoras de tributos vinculen al personal requerido no solo frente al nivel de formación, sino también en las habilidades y competencias que deben ostentar para proponer, implementar y ejecutar estrategias que permitan mejorar el recaudo y la eficiencia en los procesos tributarios de las diferentes áreas. Esta es una de las causas por las cuales el recaudo es insuficiente frente a las necesidades.

A través de la fiscalización, los entes territoriales pueden obtener mayores ingresos, ser más eficientes, fomentar la modernización de la administración tributaria y fortalecer la capacidad de controlar el proceso de identificación y liquidación de los tributos, haciendo que los contribuyentes cumplan de manera voluntaria y oportuna con sus obligaciones tributarias; por ello debe darse gran importancia a esta herramienta llamada también investigación tributaria. 


\section{Referencias}

Aguilera, M., Bernal, C. y Quintero, P. (2006). Turismo y desarrollo en el Caribe colombiano. Documentos de trabajo sobre economía regional, (79), noviembre. Banco de la República - Centro de Estudios Económicos Regionales (CEER) - Cartagena. Recuperado de http://www.banrep.gov.co/docum/Lectura_finanzas/pdf/DTSER-79.pdf

Albrecht, J. (2006). Green tax reforms for industrial transformation: overcoming institutional inertia with consumption taxes. Sustainable Development, 14(5), 300-311. DOI: http://dx.doi.org/10.1002/sd.286

Alcaldía Municipal de El Doncello. (5 de diciembre de 2017). Estatuto Tributario del municipio de El Doncello, Caquetá. Recuperado de https://eldoncellocaqueta.micolombiadigital.gov.co/sites/eldoncellocaqueta/content/files/000263/13133_acuerdomunicipal023del2017etm.pdf

Alcaldía Municipal de Pasto. (9 de abril de 2010). Estatuto Tributario del municipio de Pasto. Recuperado de https://www.pasto.gov.co/index.php/34-nuestra-entidad/ secretarias/secretaria-de-hacienda/5264-estatuto-tributario

Alfonso, M. A. (2015). La descentralización y la autonomía de los municipios en el marco del estado unitario colombiano (trabajo de grado, Universidad Militar Nueva Granada, Bogotá). Recuperado de https://repository.unimilitar.edu. co/handle/10654/14006

Arroyo, J. I. (2016). Gestión municipal desde la perspectiva de las organizaciones inteligentes y ámbito jurídico. Revista Inciso, 18(2), 127-141, diciembre. DOI: http://dx.doi.org/10.18634/incj.18v.2i.632

Bechara, A. (2015). Las regiones y su autonomía: la administración de recursos para el cumplimiento de sus funciones. Jurídicas CUC, 11(1), 345-358. DOI: http://dx.doi.org/10.17981/juridcuc.11.1.2015.16

Congreso de la República de Colombia. (1973). Ley 23 del 19 de diciembre de 1973. Por la cual se conceden facultades extraordinarias al presidente de la República para expedir el Código de Recursos Naturales y de Protección al Medio Ambiente. Bogotá: Diario Oficial 34001 del 17 de enero de 1974.

Congreso de la República de Colombia. (1991). Constitución Política de Colombia. Artículos 67, 76, 79, 80, 150, 287, 288, 311, 313 y 338. Bogotá. 
Congreso de la República de Colombia. (1993). Ley 99 del 22 de diciembre de 1993. Por la cual se crea el Ministerio del Medio Ambiente, se reordena el Sector Público encargado de la gestión y conservación del medioambiente y los recursos naturales renovables, se organiza el Sistema Nacional Ambiental - SINA y se dictan otras disposiciones. Bogotá: Diario Oficial 41146.

Congreso de la República de Colombia. (1994). Ley 136 del 2 de junio de 1994. Por la cual se dictan normas tendientes a modernizar la organización y el funcionamiento de los municipios. Bogotá: Diario Oficial 41377.

Congreso de la República de Colombia. (1994). Ley 152 del 15 de junio de 1994. Por la cual se establece la Ley Orgánica del Plan de Desarrollo. Bogotá: Diario Oficial 41450.

Congreso de la República de Colombia. (1996). Ley 300 del 26 de julio de 1996. Por la cual se expide la Ley General de Turismo. Bogotá: Diario Oficial 42845. Congreso de la República de Colombia. (2005). Ley 981 del 26 de julio de 2005. Por la cual se establece la sobretasa ambiental sobre los peajes de las vías próximas o situadas en Áreas de Conservación y Protección Municipal, sitios Ramsar o Humedales de Importancia Internacional definidos en la Ley 357 de 1997 y Reservas de Biosfera y Zonas de Amortiguación. Bogotá: Diario Oficial 45982. Congreso de la República de Colombia. (2006). Ley 1101 del 22 de noviembre de 2006. Por la cual se modifica la Ley 300 de 1996 - Ley General de Turismo. Bogotá: Diario Oficial 6461.

Congreso de la República de Colombia. (2011). Ley 1554 del 28 de junio de 2011. Por la cual se dictan normas orgánicas sobre ordenamiento territorial. Bogotá: Diario Oficial 48115.

Congreso de la República de Colombia. (2012). Ley 1558 del 10 de julio de 2012. Por la cual se modifica la Ley 300 de 1996 - Ley General de Turismo y la Ley 1101 de 2006. Bogotá: Diario Oficial 48487.

Congreso de la República de Colombia. (2012). Ley 2012 del 6 de julio de 2012. Por la cual se dictan normas para modernizar la organización y el funcionamiento de los municipios. Bogotá: Diario Oficial 48483.

Congreso de la República de Colombia. (2016). Ley 1819 del 29 de diciembre de 2016. Por medio de la cual se adopta una reforma tributaria estructural, se fortalecen los mecanismos para la lucha contra la evasión y la elusión fiscal, y se dictan otras disposiciones. Bogotá: Diario Oficial 50101. 
Consejo de Estado. (2009). Sentencia 2189 del 3 de diciembre de 2009. Radicación 730012331000200502632-0. Sección cuarta. Bogotá. Consejero Ponente: Hugo Fernando Bastidas Bárcenas.

Consejo de Estado. (2014). Sentencia 19953 de 2014. Radicación 170012331000201000331-01. Sección cuarta. Bogotá. Consejera Ponente: Martha Teresa Briceño de Valencia.

Consejo de Estado. (2015). Sentencia 16527 del 26 de febrero de 2015. Radicación 47001-23-31-000-2011-00006-02. Sección cuarta. Bogotá. Consejero Ponente: Hugo Fernando Bastidas Bárcenas.

Corte Constitucional. (1994). Sentencia C-497A del 3 de noviembre de 1994. Bogotá. Magistrado Ponente: Vladimiro Naranjo Mesa.

Corte Constitucional. (1998). Sentencia C-495 del 15 de septiembre de 1998.

Expediente D-1968. Bogotá. Magistrado Ponente: Antonio Barrera Carbonell. Corte Constitucional. (2008). Sentencia C-225 del 5 de marzo de 2008. Bogotá. Magistrado Ponente: Jaime Córdoba Triviño.

Corte Constitucional. (2011). Sentencia 76001-23-31-000-2003-00555-02(AP) del 16 de junio de 2011. Sección primera. Bogotá. Consejera Ponente: María Claudia Rojas Lasso.

Corte Constitucional. (2014). Sentencia 17001-23-31-000-2010-00331-01(19953) del 18 de junio de 2014. Sección cuarta. Bogotá. Consejera Ponente: Martha Teresa Briceño de Valencia.

Corte Constitucional. (2015). Sentencia 16527 del 22 de enero de 2015. Radicación 11001-03-06-000-2013-00530-00. Sala de consulta y servicio civil. Bogotá. Consejero Ponente: Germán Alberto Bula Escobar.

Corte Constitucional. (2017). Sentencia C-077 del 8 de febrero de 2017. Expediente D-11275 y D-11276. Bogotá. Magistrado Ponente: Luis Ernesto Vargas Silva. Departamento Administrativo de la Función Pública - DAFP. (2018). Guía de rediseño para entidades del orden territorial. Bogotá. Recuperado de https:// www.funcionpublica.gov.co/web/eva/biblioteca-virtual/-/document_library/ bGsp2IjUBdeu/view_file/34233829

Eskelinen, T. y Laitinen, A. (2015). Taxation: its justification and application to global contexts. En H. P. Gaisbauer, G. Schweiger y C. Sedmak (eds.), Philosophical explorations of justice and taxation: national and global issues. (pp. 219-236). Nueva York: Springer. DOI: http://dx.doi.org/10.1007/978-3-319-13458-1 
Jaramillo, C. y Villa, M. (2003). La sobretasa ambiental al impuesto predial: una propuesta de análisis desde la política ambiental y la hacienda pública. Ecos de Economía, (17), Medellín, octubre, 109-129.

Landes, X. (2015). Why taxing consumption: justifications, objections and social cooperation. En H. P. Gaisbauer, G. Schweiger y C. Sedmak (eds.), Philosophical explorations of justice and taxation: national and global issues. (pp. 101-117). Nueva York: Springer.

Mendoza-Bremauntz, E. (2009). Derecho económico. Ciudad de México: IURE.

Mendoza, N. C. (2015). Gestión estratégica de los municipios de sexta categoría en Colombia, el caso Agua de Dios - Cundinamarca (tesis de maestría, Universidad Militar Nueva Granada, Bogotá). Recuperado de https://repository.unimilitar.edu.co/bitstream/handle/10654/7579/ MENDOZACOLORADONELYCRISTINA2015.pdf? sequence $=1$ \&isAllowed $=\mathrm{y}$

Ministerio de Hacienda y Crédito Público. (2016). Concepto Radicado 2-2016035891 del 28 de septiembre de 2016. Dirección General de Apoyo Fiscal.

Paternina, N. (2017). Impacto del peaje La Caimanera en la oferta turística de los municipios de Santiago de Tolú y Coveñas (trabajo de grado, Universidad de Sucre, Sincelejo). Recuperado de http://repositorio.unisucre.edu.co/bitstream/001/621/1/T338.4791\%20P\%20295.pdf

PNUD. (1990). Desarrollo Humano Informe 1990. Bogotá: Tercer Mundo Editores. Recuperado de http://hdr.undp.org/sites/default/files/hdr_1990_es_completo_nostats.pdf

Presidencia de la República de Colombia. (1974). Decreto 2811 del 18 de diciembre de 1974. Por el cual se dicta el Código Nacional de Recursos Naturales Renovables y de Protección al Medio Ambiente. Bogotá: Diario Oficial 34243. Restrepo, D. (2014). El control de la construcción y el control urbano en Colombia: El caso Medellín y la Ruta Medellín Vivienda segura 2014-2024; retos y oportunidades. Revista de Ingeniería, (41), 90-94, Universidad de los Andes, Bogotá, julio-diciembre. DOI: http://dx.doi.org/10.16924/riua.v0i41.789

Schweiger, G. (2015). Taxation and the duty to alleviate poverty. En H. P., Gaisbauer, G. Schweiger y C. Sedmak (eds.), Philosophical explorations of justice and taxation: national and global issues. (pp. 33-46). Nueva York: Springer. DOI: http://dx.doi.org/10.1007/978-3-319-13458-1. 
Su Santidad Juan XXIII. (1963). Carta encíclica Pacem in terris. Sobre la paz entre todos los pueblos que ha de fundarse en la verdad, la justicia, el amor y la libertad. Recuperado de http://w2.vatican.va/content/john-xxiii/es/encyclicals/ documents/hf_j-xxiii_enc_11041963_pacem.html

Su Santidad Pablo VI. (1971). Carta apostólica Octogesima adveniens. Al señor cardenal Mauricio Roy, presidente del Consejo para los Seglares y de la Comisión Pontificia "justicia y paz" en ocasión del LXXX aniversario de la encíclica Rerum novarum. Recuperado de http://w2.vatican.va/content/paul-vi/es/ apost_letters/documents/hf_p-vi_apl_19710514_octogesima-adveniens.html

Valqui, C. y Pastor, C. (coords.). (2009). Corrientes filosóficas del derecho: una crítica antisistémica para el siglo XXI. Cajamarca, Perú: Universidad Privada Antonio Guillermo Urrelo. Recuperado de http://www.razonypalabra.org. $\mathrm{mx} / \mathrm{N} / \mathrm{N} 70 / 9 \% 20$ Libro\%20Corrientes.pdf 